\title{
Do the positions of the
}

impacted third molars affect the preoperative anxiety levels and probable postoperative pain levels of the patients?

\author{
Ahmet Taylan Çebi ${ }^{1}$, Metin Berk Kasapoğlu ${ }^{2}$ \\ ${ }^{1}$ Department Oral And Maxillofacial Surgery, Faculty of Dentistry, Karabuk University, Karabuk, Turkey \\ ${ }^{2}$ Department Oral And Maxillofacial Surgery, Faculty of Dentistry, Istanbul Unıversity, Istanbul, Turkey
}

Received: 2020-11-09.

Accepted: 2020-11-22

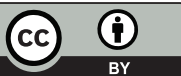

This work is licensed under Creative Commons Attribution 4.0 International License

J Clin Med Kaz 2021; 18(1):28-31

Corresponding author:

Ahmet Taylan Çebi.

E-mail: ahmettaylancebi@karabuk.edu.tr;

ORCID: https://orcid.org/0000-0001-9083-7215

\section{Abstract}

Objective: The aim of this study is to evaluate the effects of the position of the impacted third molar teeth on preoperative anxiety and possible pain levels of patients.

Material and methods: Fifty patients with impacted third molar teeth (full bone retention) in the horizontal and vertical positions were included in the study. Sociodemographic data of the patients were recorded. The patients have watched the impacted third molar surgery videos which were the position of horizontal and vertical. Subsequently, preoperative anxiety levels of patients were evaluated with The Spielberger State-Trait Anxiety Inventory-STAI part of the state anxiety inventory. In addition, pain levels that patients thought they might feel after the surgeries were evaluated with Visual Analogue Scale (VAS). $\mathrm{P}<0.05$ and $\mathrm{p}<0.001$ were considered significant in all statistical analyses.

Results: The study included 50 patients ( 25 males and 25 females) the mean age of which was $21.00 \pm 2.08$. A statistically significant difference was found between the levels of anxiety created by the positions of the impacted third molar teeth $(p<0.001, p<0.05)$. Anxiety levels were higher in female patients than in men $(p<0.001, p<0.05)$. A statistically significant difference was found between the levels of pain that patients could feel postoperatively and position of third molars $(p<0.001, p<0.05)$.

Conclusion: The positions of the third molars are associated with anxiety, stress, and postoperative pain in patients undergoing impacted third molar surgery. Addressing these factors preoperatively may reduce anxiety, probable postoperative perception of pain, and provide more positive treatment results.

Key words: Dental anxiety, postoperative pain, third molar, impacted teeth

\section{Introduction}

Anxiety symptoms may occur in minor conservative dental procedures and oral surgery as in general surgical operations [1]. Oral surgery treatments have been reported to cause greater anxiety and fear for patients than other dental treatment procedures [2]. Dental anxiety may prevent patients from completing their dental treatment, may cause patients less cooperation with the dentist during treatment, and may result in patient avoidance of surgical procedures and dissatisfaction with surgery [3]. Preoperative dental anxiety, which is generally encountered in patients before surgery procedures, adversely affects the success of the surgical procedure, the effectiveness of the anesthesia method to be applied and the recovery period in the postoperative period [4]. Among the causes of preoperative anxiety, the patient's lack of knowledge about the surgical procedure and anesthesia technique, fear of intraoperative and postoperative pain, 
anxiety of intraoperative and postoperative complications, and anxiety of deterioration of quality of life can be counted [5].

Impacted third molar surgery is a dental treatment procedure that is frequently performed in oral surgery procedures in all age groups. Postoperative sequelae such as pain, edema, trismus, infection, nerve injury may occur after the extraction of the impacted third molars for these reasons, these types of surgical procedures can be difficult for patients both physically and psychologically $[6,7]$. The anesthesia to be applied during the third molar tooth extraction, the fact that the tooth is in a difficult position in the jaw and therefore the operation will be difficult and the use of rotating instruments are the causes of anxiety [79]. This anxiety, which may occur, may cause stress to the oral surgeon performing the operation and may cause prolongation of the time of the surgical procedure and even failure [10].

It has been reported in the literature that the position of the impacted third molars and clinical and anatomic factors determines the degree of difficulty of the surgical procedure [1113]. Preoperative anxiety level increases in patients according to the difficulty level of the surgical procedure [7-9]. Therefore, in this study, it was aimed to evaluate the effects of the positions of the impacted third molars on preoperative anxiety levels in patients.

The hypothesis of this study is to assume that when oral surgeons fully understand what the source of patients anxiety is, the extraction of impacted third molar will be facilitated, and the evaluation of these issues will reduce the preoperative anxiety and postoperative pain levels of patients. Thus, the aim of this study was to evaluate the effect of the position of the impacted third molar teeth on preoperative anxiety in patients and evaluate the expected pain levels depending on the embedded position of the tooth of the patients.

\section{Material and methods}

The study was started after the decision of the Ethics Committee dated 13.12.2018 and numbered 13/1 and detailed information was given to all patients participating in the study, the consent form was signed. The study was conducted in accordance with the principles of the Helsinki Declaration of Human Rights. The study was conducted on a total of 50 patients aged from 18-24 years with bilateral impacted mandibular third molar, admitted to the Department of Oral and Maxillofacial Surgery. The number of patients to be included in the study was decided as a result of power analysis. Inclusion criteria from the study were; patients with an impacted third molar in the vertical position and full-bone retention on one side and in the horizontal position and full-bone retention on the other side. Exclusion criteria included the presence of a psychological and neurological disease diagnosed and treated, the patients 'unwillingness to participate in the study voluntarily, and the patients' vision and hearing problems.

Sociodemographic characteristics of the patients such as gender and age were recorded. Anxiety levels of the patients were evaluated by using the The Spielberger State-Trait Anxiety Inventory-STAI part of the state anxiety inventory [14]. The STAI questionnaire comprises two separate scales that measure two independent concepts: the anxiety-trait (STAI-T) and the anxiety-state (STAI-S). While the part that measures traitanxiety helps to measure the feelings of the individual in the last week, the state-anxiety part is planned to measure the momentary feelings of the individual.

After detailed radiological and clinical examinations of the patient's, the surgical operation was indicated. Firstly, patients

who accepted to undergo surgery underwent a video (The same Youtube video presentation showing anesthesia technique and impacted third molar surgery) demonstration of the impacted third molar surgery in the vertical position and full-bone retention. Immediately afterward, the STAI-S questionnaire was given for preoperative anxiety assessment to patients. In addition, each patient was asked the questions by the researcher, 'How severe will your postoperative pain be?'. The patients were asked to make probable postoperative pain assessments on a 10 $\mathrm{cm}$ Visual Analogue Scale (VAS). The patients were asked to rest in the waiting room for 45 minutes. After the rest period, the patients were called to the clinic again. This time, patients were watched the other surgical video which was impacted third molar in the horizontal position and full-bone retention. Immediately afterward, the STAI-S questionnaire was given for preoperative anxiety assessment and VAS was given for probable postoperative pain assessments to patients.

The data obtained were evaluated with Minitab 17 statistical data analysis program. Descriptive statistical analyzes (mean, standard deviation, frequency) were used in the analysis of statistical data. Shapiro-Wilk test was used to determine whether the data were suitable for normal distribution. Student t-test was used to compare parametric data between two groups. The results of all analyzes were evaluated as $p<0.05$ and $p<0.001$.

\section{Results}

The study included 50 patients ( 25 males and 25 females) aged between 18 and 24 years. The mean age of the patients included in this study was $21.00 \pm 2.08$. The mean age of female patients was $20.96 \pm 2.15$ years and the mean age of male patients was $21.04 \pm 2.07$ years. There was no statistically significant difference between the mean age of female and male patients $(\mathrm{p}=0,879, \mathrm{p}>0.05)$ (Table 1).

Table 1

\begin{tabular}{|l|l|l|l|}
\hline & Male & Female & $\mathrm{p}$ value \\
\hline Sex & $25(\% 50)$ & $25(\% 50)$ & \\
\hline Age (Mean \pm SD) & $21.04 \pm 2.07$ & $20.96 \pm 2.15$ & 0,879 \\
\hline Total Age (Mean \pm SD) & $21.00 \pm 2.08$. & \\
\hline
\end{tabular}

Student test

A statistically significant difference was found between the effects of the positions of third molar teeth on anxiety levels. It has been found that the surgeries of the impacted teeth in the horizontal position cause more severe anxiety than in the vertical position on the patients $(\mathrm{p}=0.000, \mathrm{p}<0.001)$ (Table 2 ).

\begin{tabular}{|c|c|c|c|}
\hline Table 2 & $\begin{array}{l}\text { STAI-S scores, rela } \\
\text { position of impac }\end{array}$ & $\begin{array}{l}\text { nships with any } \\
\text { third molars }\end{array}$ & nd \\
\hline \multirow[t]{2}{*}{ STAI-S } & $\begin{array}{l}\text { Vertical position } \\
\text { impacted third molar }\end{array}$ & $\begin{array}{l}\text { Horizontal position } \\
\text { impacted third } \\
\text { molar }\end{array}$ & \multirow[t]{2}{*}{$\mathrm{p}$ value } \\
\hline & Mean \pm SD & Mean \pm SD & \\
\hline Female patients & $45.92 \pm 12.43$ & $54.48 \pm 13.26$ & $0.000^{* *}$ \\
\hline Male patients & $42.04 \pm 12.18$ & $44.16 \pm 11.74$ & 0.038* \\
\hline $1 \mathrm{p}$ & $0.025^{*}$ & $0.000^{* *}$ & \\
\hline Total patients & $43.98 \pm 12.33$ & $49.32 \pm 13.45$ & $0.000 * *$ \\
\hline
\end{tabular}

\section{Student t test}

${ }^{*} p<0.05$

${ }^{* *} p<0.001$

作

P: comparison of STAI-S levels according to the position of impacted third molar 
A statistically significant difference was found between the effects of the positions of third molar teeth on anxiety levels in female patients. It has been found that the surgeries of the teeth impacted in the horizontal position cause more severe anxiety than in the vertical position, in female patients. $(p=0.000$, $\mathrm{p}<0.001$ ) (Table 2). A statistically significant difference was found between the effects of the positions of third molar teeth on anxiety levels in male patients. It has been found that the surgeries of the teeth impacted in the horizontal position cause more severe anxiety than in the vertical position, in male patients $(\mathrm{p}=0.038, \mathrm{p}<0.05)($ Table 2$)$.

A statistically difference was found between male and female patients in the level of anxiety in the vertically positioned impacted third molar surgery. Anxiety level was higher in female patients $(p=0.025, p<0.05)$ (Table 2$)$. A statistically significant difference was found between male and female patients in the level of anxiety in the horizontally positioned impacted third molar surgery. Anxiety level was higher in female patients $(\mathrm{p}=0.000, \mathrm{p}<0.001)$ (Table 2).

A statistically significant difference was also found between the pain levels expected (probable pain assessments) by the patients after surgery. Patients reported that more severe pain may occur after surgery of the impacted mandibular third molar in the horizontal position $(p=0.000, p<0.001)$ (Table 3$)$.

\begin{tabular}{|c|c|c|c|}
\hline Table 3 & $\begin{array}{l}\text { AS scores, relationsh } \\
\text { sessments and posi }\end{array}$ & $\begin{array}{l}\text { os with probable } p \\
\text { ion of impacted th }\end{array}$ & in molars \\
\hline \multirow[t]{2}{*}{$\begin{array}{l}\text { Probable Pain } \\
\text { Assessments } \\
\text { (VAS) Score }\end{array}$} & $\begin{array}{l}\text { Vertical position } \\
\text { impacted third molar }\end{array}$ & $\begin{array}{l}\text { Horizontal position } \\
\text { impacted third } \\
\text { molar }\end{array}$ & $\mathrm{p}$ value \\
\hline & Mean \pm SD & Mean \pm SD & \\
\hline Female patients & $5.92 \pm 1.65$ & $7.20 \pm 1.15$ & $0.004^{*}$ \\
\hline Male patients & $5.00 \pm 1.32$ & $6.08 \pm 1.35$ & 0.003* \\
\hline $1 \mathrm{p}$ & $0.032 *$ & $0.000 * *$ & \\
\hline Total patients & $5.46 \pm 1.55$ & $6.64 \pm 1.36$ & $0.000^{* *}$ \\
\hline \multicolumn{4}{|c|}{${ }^{*} p<0.05$} \\
\hline
\end{tabular}

A statistically difference was also found between the pain levels expected (probable pain assessments) by female patients after surgery. Female patients reported that more severe pain may occur after surgery of the impacted mandibular third molar in the horizontal position $(\mathrm{p}=0.004, \mathrm{p}<0.05)$ (Table 3$)$. A statistically difference was also found between the pain levels expected (probable pain assessments) by male patients after surgery. Patients of male reported that more severe pain may occur after surgery of the impacted mandibular third molar in the horizontal position $(\mathrm{p}=0.003, \mathrm{p}<0.05)$ (Table 3$)$.

A statistical difference was also found between the pain levels expected (probable pain assessments) by patients after surgery. Female patients reported that more severe pain may occur than male patients after surgery of the impacted mandibular third molar in the horizontal $(\mathrm{p}=0.000, \mathrm{p}<0.001)$ (Table 3$)$ and vertical position $(\mathrm{p}=0.032, \mathrm{p}<0.05)$ (Table 3$)$.

\section{Discussion}

Impacted third molar surgeries have always been a fearful surgical procedure due to intraoperative and postoperative complications, morbidity, surgical difficulty, and fear of surgery and operating room $[15,16]$. In addition, the trauma process of the bone, muscle, and soft tissue in the associated region creates extreme anxiety for the patients after the impacted third molar surgeries [17]. In the present study, the effect of the position of the impacted third molar teeth on the anxiety level and the expected pain level after the impacted third molar surgery was investigated.

STAI has been used in most studies to assess anxiety in impacted third molar surgeries [18,19]. In this study, STAI-S was used to evaluate the effect of the positions of impacted third molar teeth on anxiety in patients, compatible with the other papers in literature.

The present study was found that females have a higher anxiety level than males in impacted third molar surgery procedures. These results confirmed similar results of previous researches in the literature that showed higher levels of anxiety among females $[20,21]$. On the other side, some studies in the literature have not found any difference in anxiety levels between males and females in oral surgery procedures [10,22].

The postoperative pain and anxiety relationship has been researched in many articles in the literature [18]. Granot et al. reported that postoperative pain levels of patients undergoing abdominal surgery can be estimated by evaluating their preoperative anxiety levels [23]. Taenzer et al reported in the study that anxiety levels of patients undergoing elective gallbladder surgery were related to postoperative pain levels [24]. In the present study, patients with high preoperative anxiety levels reported that they would likely experience excessive pain levels after third molar surgery.

Susarla and Dodson reported that the difficulty of the third molar extraction was affected by three different groups of factors: anatomical, operative and demographic [25,26]. According to this information, the surgical difficulty is affected by anatomical and surgical variables. The position of the third molar tooth within the bone is included in both anatomical and surgical variables. In addition, the position of the impacted third molar affects the difficulty of the surgical procedure [12]. The difficulty of the surgical procedure also affects the patient's anxiety level [7-9]. The need for bone osteotomy and tooth sectioning in surgical tooth extractions be made the extraction more complex and more difficult. Surgeries of the impacted third molar in the horizontal position is performed more bone osteotomy and tooth sectioning. In the results of the current study, it was found that the extraction of the impacted third molar in the horizontal position causes more anxiety than the extraction of the third molar in the vertical position.

Wang et al. evaluated the levels of anxiety and postoperative pain in patients who underwent third molar surgery in a horizontal position. They stated that the reason for choosing the third molar surgeries in the horizontally-impacted position was the most difficult procedure in the impacted third molar operations [27]. In the present study, the anxiety effects on the patients of the positions of the impacted third molar teeth were evaluated. It has been determined that the surgical operations of the impacted third molars in the horizontal position create a more severe anxiety level in the patients.

Consequently, impacted third molar surgeries increase the anxiety levels of the patients as it creates a stressful, complex surgery, difficult, and painful impression on the patients. Impacted third molar surgeries in the horizontal position with the thought that it will be more difficult, complex, and postoperative more painful in the opinion of the patients create more dental fear and anxiety in patients than surgeries of other positions of impacted third molars.

Disclosures: There is no conflict of interest for all authors.

Acknowledgements: None

Funding: None 


\section{References}

1. Aznar-Arasa L, Figueiredo R, Valmaseda-Castellón E, Gay-Escoda C. Patient anxiety and surgical difficulty in impacted lower third molar extractions: a prospective cohort study. Int J Oral Maxillofac Surg. 2014; 43(9):1131-6. doi:10.1016/j.ijom.2014.04.005

2. Kazancioglu HO, Tek M, Ezirganli S, Demirtas N. Does watching a video on third molar surgery increase patients' anxiety level? Oral Surg Oral Med Oral Pathol Oral Radiol. 2015; 119(3):272-7. doi:10.1016/j.0ooo.2014.10.012

3. González-Lemonnier S, Bovaira-Forner M, Peñarrocha- Diago M, Peñarrocha-Oltra D. Relationship between preoperative anxiety and postoperative satisfaction in dental implant surgery with intra venous conscious sedation. Med Oral Patol Oral Cir Bucal. 2010; 15(2):379-82. doi:10.4317/medoral.15.e379

4. Lago-Mendez L, Diniz-Freitas M, Senra-Rivera C, Gude-Sampedro F, Gándara Rey JM, García-García A. Relationships between surgical difficulty and postoperative pain in lower third molar extractions. J Oral Maxillofac Surg. 2007; 65(5):979-83. doi:10.1016/j. joms.2006.06.281

5. Jlala HA, French JL, Foxall GL, Hardman JG, Bedforth NM. Effect of preoperative multimedia information on periopoerative anxiety in patients undergoing procedures under regional anaesthesia. Br J Anaesth. 2010; 104(3):369-74. doi:10.1093/bja/aeq002

6. Hwang JK, Kim KW. Complications of impacted third molar extraction: retrospective study. J Korean Assoc Oral Maxillofac Surg. 2010; 36(2):119-24. doi:http://doi.org/10.5125/jkaoms.2010.36.2.119

7. Yusa H, Onizawa K, Hori M, Takeda S, Takeda H, Fukushima S, et al. Anxiety measurements in university students undergoing third molar extraction. Oral Surg Oral Med Oral Pathol Oral Radiol Endod. 2004; 98(1):23-7. doi:10.1016/j.tripleo.2003.12.017

8. Hollander MHJ, Schortinghuis J, Vissink A. Changes in heart rate during third molar surgery. Int J Oral Maxillofac Surg. 2016; 45(12):1652-7. https://doi.org/10.1016/j.ijom.2016.08.004

9. Humphris GM, Freeman R, Campbell J, Tuutti H, D'Souza V. Further evidence for the reliability and validity of the Modified Dental Anxiety Scale. Int Dent J. 2000; 50(6):367-370. doi:10.1111/j.1875-595x.2000.tb00570.x

10. Thomson WM, Locker D, Poulton R. Incidence of dental anxiety in young adults in relation to dental treatment experience. Community Dent Oral Epidemiol. 2000; 28(4):289-294. doi:10.1034/j.1600-0528.2000.280407.x

11. Akadiri OA, Fasola AO, Arotiba JT. Evaluation of Pederson index as an instrument for predicting difficulty of third molar surgical extraction. Niger Postgrad Med J. 2009; 16(2):105-8. PMID: 19606189

12. Bali A, Bali D, Sharma A, Verma G. Is Pederson index a true predictive difficulty index for impacted mandibular third molar surgery? A meta-analysis. J Maxillofac Oral Surg. 2013; 12(3):359-64. doi:10.1007/s12663-012-0435-x

13. Roy I, Baliga SD, Louis A, Rao S. Importance of clinical and radiological parameters in assessment of surgical difficulty in removal of impacted mandibular 3rd molars: a new index. J Maxillofac Oral Surg. 2015; 14(3):745-9. doi:10.1007/s12663-014-0731-8

14. Spielberger CD, Gorsuch RL, Lushene RE, Vagg PR, Jacobs GA. Manual for State and Trait Anxiety Inventory. Consulting Psychologists Press: Palo Alto. 1983.

15. Asutay F, Yolcu Ü, Geçör O, Acar AH, Öztürk SA, Malkoç S. An evaluation of effects of platelet-rich-fibrin on postoperative morbidities after lower third molar surgery. Niger J Clin Pract. 2017; 20(12):1531-6. doi:10.4103/1119-3077.181400

16. Mahdey HM, Arora S, Wei M. Prevalence and Difficulty Index Associated with the 3rd Mandibular Molar Impaction among Malaysian Ethnicities: A Clinico-Radiographic Study. JCDR. 2015; 9(9):65-68. doi:10.7860/JCDR/2015/14490.6509

17. 17. Brasileiro BF, de Braganca RM, Van Sickels JE. An evaluation of patients' knowledge about perioperative information for third molar removal. J Oral Maxillofac Surg. 2012; 70(1):12-8. doi: 10.1016/j.joms.2011.06.225

18. Kvale G, Berggren U, Milgrom P. Dental fear in adults: a metaanalysis of behavioral interventions. Community Dent Oral Epidemiol. 2004; 32(4):250-64. doi:10.1111/j.1600-0528.2004.00146.x

19. Van Wijk A, Lindeboom J. The effect of a separate consultation on anxiety levels before third molar surgery. Oral Surg Oral Med Oral Pathol Oral Radiol Endod. 2008; 105(3):303-307. doi: 10.1016/j.tripleo.2007.07.028

20. Doerr PA, Lang WP, Nyquist LV, Ronis DL. Factors associated with dental anxiety. J Am Dent Assoc. 1998; 129(8):1111-9. doi:10.14219/ jada.archive.1998.0386

21. Kazancioglu HO, Dahhan AS, Acar AH. How could multimedia information about dental implant surgery effects patients' anxiety level? Med Oral Patol Oral Cir Bucal. 2017; 22(1):102-7. doi:10.4317/medoral.21254

22. Economou GC. Dental anxiety and personality: investigating the relationship between dental anxiety and self-consciousness. $J$ Dental Educ. 2003; 67(9):970-80. PMID: 14518835

23. Granot M, Ferber SG. The roles of pain catastrophizing and anxiety in the prediction of postoperative pain intensity: a prospective study. Clin J Pain. 2005; 21(5):439-45. doi:10.1097/01.ajp.0000135236.12705.2d

24. Taenzer P, Melzack R, Jeans ME. Influence of psychological factors on postoperative pain, mood and analgesic requirements. Pain. 1986; 24(3):331-42. doi:10.1016/0304-3959(86)90119-3

25. Susarla SM, Dodson TB. Risk factors for third molar extraction difficulty. JOral Maxillofac Surg. 2004; 62(11):1363-1371. doi:10.1016/j. joms.2004.05.214

26. Susarla SM, Dodson TB. Estimating third molar extraction difficulty: a comparison of subjective and objective factors. J Oral Maxillofac Surg. 2005; 63(4):427-434. doi:10.1016/j.joms.2004.12.003

27. Wang TF, Wu YT, Tseng CF, Chou C. Associations between dental anxiety and postoperative pain following extraction of horizontally impacted wisdom teeth: A prospective observational study. Medicine (Baltimore). 2017; 96(47):8665. doi:10.1097/ MD.0000000000008665 